\title{
Recovery of Lactobacillus casei strain Shirota (LcS) from faeces of healthy Singapore adults after intake of fermented milk
}

\author{
W.W.T. Khine ${ }^{1,2}$, X.J. Ang ${ }^{3}$, Y.S. Chan ${ }^{3}$, W.Q. Lee ${ }^{3}$, S.Y. Quek ${ }^{3}$, S.H. Tan ${ }^{3}$, H.T.A. Teo ${ }^{1}$, J.K.B. Teo ${ }^{3}$, Q.C. Lau ${ }^{3}$ and \\ Y-K. Lee Li, $^{*}$ \\ ${ }^{1}$ Department of Microbiology \& Immunology, Yong Loo Lin School of Medicine, National University of Singapore, 5 Science \\ Drive 2, Singapore 117545, Singapore; ${ }^{2}$ Functional Food Forum, Faculty of Medicine, University of Turku, Turku 20014, \\ Finland; ${ }^{3}$ Ngee Ann Polytechnic, 535, Clementi Road, Singapore S599489, Singapore; ${ }^{4}$ Department of Surgery, National \\ University of Hospital, Tower Block, 1 E Kent Ridge Road, Singapore 119228, Singapore; micleeyk@nus.edu.sg
}

Received: 12 December 2018 / Accepted: 31 May 2019

(c) 2019 Wageningen Academic Publishers

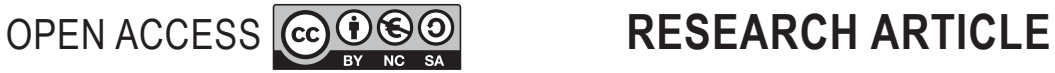

\begin{abstract}
To validate survival of Lactobacillus casei strain Shirota (LcS) during passage through the gastrointestinal tract of healthy Singaporean young adults, 21 participants (18-25 years old) were asked to consume a $100 \mathrm{ml}$ of fermented milk drink containing $1.0 \times 10^{8} \mathrm{cfu} / \mathrm{ml}$ of LcS daily for 14 days, and to maintain their dietary habit and life style. During and at the end of the ingestion period, both culture method (identity confirmed by ELISA) and 16s rRNA sequencing results revealed that viable LcS (7.27 and $7.64 \log _{10} \mathrm{cfu} / \mathrm{g}$ of faeces at the ingestion period Day 7 and Day 14, respectively) and Lactobacillus could be recovered from the faeces of all the subjects. The viable LcS count from male and female were comparable for each time point. Before consumption (baseline) and 14 days after cessation of consumption of the fermented milk, LcS was not detected in most of the subjects. In this study condition, the composition of the major gut microbiota ( $>0.1 \%$ in relative abundance of genus) and characteristics of defaecation such as stool consistency and frequency of defecation did not change throughout the study before and after ingestion of LcS. LcS was able to survive passage through the gastrointestinal tract of Singapore adults without sustainable colonisation, but the effect of LcS on microbiota modulation, stool consistency and frequency was not observed under this study condition.
\end{abstract}

Keywords: probiotics, Lactobacillus casei strain Shirota, health

\section{Introduction}

The microbiota in human host refers to the colonisation of microorganisms, such as fungi, bacteria, and archaea on the various habitats within the human host. The large abundance of microbes within the body establishes its basis for microbial symbiosis where these microbes play a role in the modulation of human health and physiology (Turnbaugh et al., 2007). The gut microbiota makes up more than $50 \%$ of the total microbes that colonise the entire human body (Rodríguez et al., 2015), and it is no doubt that the large abundance of gut microbiota plays an important role in the modulation of human health. For example, the presence of Lactobacillus in the gut serves to protect against pathogenic infections (Shu and Gill, 2002). Moreover, changes in the gut microbiota composition could also affect the health status of the host. Imbalance microbiome in the gut has been implicated in the pathogenesis of diseases, such as allergic disorders and irritable bowel disease (DeGruttola et al., 2016). As such, the knowledge in gut microbiota composition and their relative abundance could potentially have an impact on human health paves the way for future studies on the possible use of gut microbiota to promote health.

In recent decades, probiotics have been widely available in the consumer market and are very often marketed as a functional food. Probiotics are foods or supplements that contain live microbes (Ziemer and Gibson, 1998) and adequate consumption of these probiotics have been 
suggested to bring about beneficial health effect to the host (Kechagia et al., 2013). Commonly used probiotics are lactic acid bacteria such as Lactobacillus and Bifidobacterium with the various strains (Hemarajata and Versalovic, 2013). The main health benefits of probiotics are an enhancement of immunity against intestinal infections, modulation of human intestinal microbiota, prevention of diarrhoea disease, colon cancer, hypercholesterolemia, and gastrointestinal tract disease, and improvement in lactose utilisation, and stabilisation of the gut mucosal barrier (Kailasapathy and James, 2000). The probiotic efficacy relies on their ability to survive passage in the digestive system. The ability of Lactobacillus and Bifidobacterium to survive in the gastrointestinal tract varies between species and strains considerably (Guergoletto et al., 2010). With the possibility of different probiotics exerting different effects on the host, it is thus important that the study utilises a single strain of probiotic, where the effect on the gut microbiota could be certain that it results from the specific probiotic used.

The Lactobacillus casei strain Shirota (LcS) is an exclusively registered probiotic strain that is used in the fermented milk products of Yakult Honsha Co., Ltd. (Tokyo, Japan). Numerous studies have been conducted to investigate the beneficial effect of LcS. The introduction of LcS in the gut has been suggested in studies to prevent bladder cancer recurrence (Aso and Akazan, 1992). Studies have also suggested that the bacteria are able to suppress foodinduced allergies and anaphylaxis (Shida et al., 2002). Consumption of the probiotic could also potentially be used as a health-promoting tactic to combat obesity. A pilot study has shown that this strain of probiotic is able to effectively improve lipid metabolism of the host thereby promoting weight loss (Wang et al., 2017). With the numerous health benefits that accompany the consumption of $\mathrm{LcS}$, it is thus important to investigate if its consumption leads to similar effects in subjects with varying baseline gut microbiota profile or genetic background. The survivability in the gastrointestinal tract is one of the most important features of probiotics, and that of was assessed in different regions and countries (Japan (Yuki et al., 1999), Thailand (Tiengrim et al., 2012), China (Wang et al., 2015), UK (Sakai et al., 2010), Vietnam (Mai et al., 2017), and Indonesia (Utami et al., 2015). The survival of LcS through gut might be associated with factors such as type and composition of food consumed, lifestyle, environment, and race. For this reason, we investigate the recovery of viable LcS in Singapore adults who had different lifestyle, food habit, and the living environment from other countries.

\section{Materials and methods}

Twenty-seven healthy Chinese Singaporean adults of 1825 years old were recruited. The subjects who are going to be 18 years old were also included in the study. Six subjects were rejected because of having fermented dairy products except for study products during the study period or unwillingness of the subjects to complete the study or difficulties in sample storage or absence during the study. The duration of the study for each subject was 42 days (Figure 1). This includes 14 days baseline period, 14 days ingestion period and 14 days follow up period. At the start of the recruitment, the subjects were instructed to abstain from the consumption of all probiotic food/beverages and fermented food, such as kimchi, tempeh, and cheese among many others. During the ingestion period, each subject consumed one bottle of study product per day (Yakult drink, containing 10 billion $\mathrm{LcS}$, after lunch), and instructed to maintain their dietary habit and lifestyle, to remove these potential confounding factors. During the study, daily food intake, concomitant medications, and bowel movement were recorded. Faecal samples were collected before, during ingestion and post ingestion at specific time points. The stool characteristic was recorded and determined based on the Bristol Stool Form Scale (Lewis and Heaton, 1997). The number of viable LcS was investigated using the culture method and confirmed by Enzyme-linked Immunosorbent Assay (ELISA). The monoclonal antibody for $\mathrm{LcS}$ was a gift from Yakult Central Institute, Japan. The gut microbiome profile was also analysed using $16 \mathrm{~S}$ rRNA sequencing.

Faecal DNA was extracted using phenol-chloroform and ethanol DNA precipitation after washing the samples. Then,

\begin{tabular}{|c|c|c|c|}
\hline$n=21$ & Baseline period & Ingestion period & Follow-up period \\
\hline Product ingestion & no & yes & no \\
\hline Duration & 14 days & 14 days & 14 days \\
\hline Day & & $\begin{array}{l}1 \\
21 \\
\Delta\end{array}$ & 8 \\
\hline
\end{tabular}

Figure 1. Schematic diagram of study design. 14 days last for ingestion and follow-up periods, respectively. Four time points for faecal samples collection at baseline, ingestion day 7 , ingestion day 14 and end of follow-up. $n=$ number of subjects. 
the concentration of dsDNA was accurately quantified by the PicoGreen fluorescent based method. The extracted DNA was amplified at V3-V4 region of the 16S rRNA gene followed by the addition of indices to the purified amplicons for individual sample barcoding purpose. The DNA library was checked for its quantity and quality by each sample. The libraries were adjusted for their concentration and then pooled together. The pooled library was quantified again by qPCR to adjust the concentration and was loaded into the MiSeq sequencing system (Illumina, New York, NY, USA) after denaturation. After the run was completed, the demultiplexed reads were further analysed using the Quantitative Insights Into Microbial Ecology (QIIME) bioinformatic pipeline (Caporaso et al., 2010; Kuczynski et al., 2012) and Greengene bacterial database (gg 13_8). The appropriate graphs and statistical analysis were done by GraphPad Prism 7 (GraphPad, Inc., San Diego, CA, USA) software and Canoco5 (Microcomputer Power, Ithaca, NY, USA) software and R 3.5.2 software (RStudio, Inc., Boston, MA, USA). For statistical analysis, a non-parametric test of Friedman test and Nemenyi post-hoc pairwise comparison test were performed to find the significant differences of stool consistency, the frequency of defecation and the relative abundance of the bacterial genera across the time points. Permutational multivariate analysis of variance (PERMANOVA) test was used to compare the dissimilarities of the bacterial communities in Principle coordinate analysis (PCoA).

\section{Results}

The biodata of the subjects is summarised in Table 1. The LcS concentration was enumerated by culture method and its identity confirmed by ELISA method. The results are summarised in Table 2.

LcS was found in faecal samples of six participants after the baseline period at an average of $5.29 \log _{10} \mathrm{cfu} / \mathrm{g}$ of faeces. During the ingestion period (Ingestion Day 7 and Day 14), LcS was detected at an average of $7.27 \log _{10} \mathrm{cfu} / \mathrm{g}$ of faeces and $7.64 \log _{10} \mathrm{cfu} / \mathrm{g}$ of faeces in all the subjects $(n=21)$ respectively. $\mathrm{LcS}$ was only detected in the faeces of five volunteers on the $42^{\text {th }}$ day (at the end of follow-up period) at an average of $6.97 \log _{10} \mathrm{cfu} / \mathrm{g}$ of faeces.

Table 1. Biodata of subjects (mean \pm standard deviation).

$\begin{array}{ll}\text { Age (years) } & 18.8 \pm 1.0 \\ \text { Height }(\mathrm{cm}) & 164.4 \pm 0.1 \\ \text { Weight }(\mathrm{kg}) & 60.3 \pm 11.0 \\ \text { Body Mass Index }\left(\mathrm{kg} / \mathrm{m}^{2}\right) & 22.1 \pm 3.0 \\ \text { Gender }(\mathrm{n}) & \\ \text { Female } & 14 \\ \text { Male } & 7\end{array}$

Among the male and female subjects, LcS was found in faecal samples of one out of seven and five out of 14 participants after the baseline period respectively. During the ingestion Day 7, LcS was detected at an average of 7.26 and $7.28 \log _{10} \mathrm{cfu} / \mathrm{g}$ of faeces for males and females, respectively. On ingestion Day 14, LcS counts for males and females were 7.66 and $7.62 \log _{10} \mathrm{cfu} / \mathrm{g}$ of faeces, respectively. $\mathrm{LcS}$ was only detected in the faeces of one male and four female volunteers at the end of follow-up period.

The stool consistency scale was not statistically significant by Friedman test (Figure 2A). However, the frequency of defecation (Table 3) was statistically significant by Friedman test at a $P$-value of 0.021 , but not statistically significant between each time point by Nemenyi post-hoc pairwise comparison test (Figure 2B).

Gut bacterial communities from any two time points were not statistically significant as performed by permutational multivariate analysis of variance (PERMANOVA) (Supplementary Table S1). The overall bacterial profile of both genders as well as each gender was shown in Figure 3. In the analysis of both genders, except for Lactobacillus, there were no significant difference between each time point using both the Friedman test and Nemenyi post-hoc pairwise comparison test (Supplementary Tables S2, S5 and S8). In the analysis of male and female, statistical difference was detected in various genus including Lactobacillus (Supplementary Tables S3, S4, S6, S7, S9 and S10).

As shown in Figure 4, Nemenyi post-hoc pairwise comparison test was performed for comparison of the relative abundance of Lactobacillus. Statistical differences could be seen between baseline and during the ingestion period and between during and post-ingestion period in both gender and each gender (Figure 4 and Supplementary Tables S8-S10).

\section{Discussion}

During the ingestion period, the LcS was detected at a relatively high abundance in all the subject's stools. This result indicates that the LcS in the tested fermented milk is able to survive passage through the gastrointestinal tract of Singapore adults and this confirms previous similar reports on the recovery of $\mathrm{LcS}$ in other countries (Mai et al., 2017; Sakai et al., 2010; Tienrim et al., 2012; Utami et al., 2015; Wang et al., 2015; Yuki et al., 1999). Recovery of LcS from one subject decreased to $2.85 \log _{10} \mathrm{cfu} / \mathrm{g}$ faeces in the second week of ingestion, which reason is unknown.

In this study, the LcS was not detected in most of the subjects $(16 / 21)$ in 14 days after consumption of the fermented milk. However, it was only detected in five subjects after consumption was stopped. This shows variation in LcS persistence during the wash-out period. The persistent 
Table 2. Enumeration of faecal LcS, based on culture and ELISA method. ${ }^{1}$

\begin{tabular}{|c|c|c|c|c|}
\hline \multirow[t]{2}{*}{ Subject IDs } & \multirow[t]{2}{*}{ Baseline } & \multicolumn{2}{|l|}{ Ingestion } & \multirow[t]{2}{*}{ Follow-up } \\
\hline & & Day 7 & Day 14 & \\
\hline S1 (female) & $\mathrm{ND}, 0.00^{*}$ & $5.57,371,535.23^{*}$ & $6.53,3,388,441.56^{*}$ & $N D, 0.00^{*}$ \\
\hline S2 (female) & $3.04,1,096.48^{*}$ & $7.00,10,000,000^{*}$ & $2.85,707.95^{\star}$ & $N D, 0.00^{*}$ \\
\hline S3 (female) & $\mathrm{ND}, 0.00^{*}$ & $7.92,83,176,377.11^{*}$ & $7.98,95,499,258.60^{*}$ & $\mathrm{ND}, 0.00^{*}$ \\
\hline S4 (female) & $\mathrm{ND}, 0.00^{*}$ & $6.26,1,819,700.86^{*}$ & $7.37,23,442,288.15^{\star}$ & $\mathrm{ND}, 0.00^{*}$ \\
\hline S5 (female) & $\mathrm{ND}, 0.00^{*}$ & $6.54,3,467,368.50^{*}$ & $7.01,10,232,929.92^{*}$ & $\mathrm{ND}, 0.00^{*}$ \\
\hline S6 (female) & $N D, 0.00^{*}$ & $6.88,7,585,775.75^{\star}$ & $6.34,2,187,761.62^{*}$ & $\mathrm{ND}, 0.00^{*}$ \\
\hline S7 (female) & $\mathrm{ND}, 0.00^{*}$ & $5.64,436,515.83^{*}$ & $7.58,38,018,939.63^{*}$ & $\mathrm{ND}, 0.00^{*}$ \\
\hline S8 (male) & $\mathrm{ND}, 0.00^{*}$ & $6.93,8,511,380.38^{*}$ & $7.50,31,622,776.60^{*}$ & $\mathrm{ND}, 0.00^{*}$ \\
\hline S9 (male) & $\mathrm{ND}, 0.00^{*}$ & $6.71,5,128,613.84^{*}$ & $7.06,11,481,536.21^{*}$ & $N D, 0.00^{*}$ \\
\hline S10 (male) & $N D, 0.00^{*}$ & $7.57,37,153,522.91^{*}$ & $7.44,27,542,287.03^{*}$ & $N D, 0.00^{*}$ \\
\hline S11 (female) & $\mathrm{ND}, 0.00^{*}$ & $6.32,2,089,296.13^{*}$ & $6.96,9,120,108.39^{*}$ & $\mathrm{ND}, 0.00^{*}$ \\
\hline S12 (female) & $5.11,128,824.96^{*}$ & $7.00,10,000,000^{*}$ & $6.43,2,691,534.80^{*}$ & $\mathrm{ND}, 0.00^{*}$ \\
\hline S13 (female) & $5.03,107,151.93^{*}$ & $7.07,11,748,975.55^{*}$ & $8.51,323,593,656.93^{*}$ & $8.29,194,984,459.98 *$ \\
\hline S14 (female) & $2.58,380.19^{*}$ & $6.52,3,311,311.21^{*}$ & $7.80,63,095,734.45^{\star}$ & $4.34,21,877.62^{*}$ \\
\hline S15 (female) & $3.19,1,548.82^{*}$ & $7.49,30,902,954.33^{*}$ & $6.00,1,000,000^{*}$ & $5.45,281,838.29^{*}$ \\
\hline S16 (female) & $\mathrm{ND}, 0.00^{*}$ & $7.32,20,892,961.31^{*}$ & $6.58,3,801,893.96^{*}$ & $5.82,660,693.45^{*}$ \\
\hline S17 (female) & $\mathrm{ND}, 0.00^{*}$ & $7.91,81,283,051.62^{*}$ & $7.13,13,489,628.83^{*}$ & $\mathrm{ND}, 0.00^{*}$ \\
\hline S18 (male) & $6.59,3,890,451.45^{*}$ & $6.65,4,466,835.92^{*}$ & $7.95,89,125,093.81^{*}$ & $N D, 0.00^{*}$ \\
\hline S19 (male) & $\mathrm{ND}, 0.00^{*}$ & $7.00,10,000,000^{*}$ & $6.07,1,174,897.55^{\star}$ & $3.30,1995.26^{*}$ \\
\hline S20 (male) & $\mathrm{ND}, 0.00^{*}$ & $7.49,30,902,954.33^{*}$ & $7.99,97,723,722.10^{*}$ & $\mathrm{ND}, 0.00^{*}$ \\
\hline S21 (male) & $\mathrm{ND}, 0.00^{*}$ & $7.50,31,622,776.60^{*}$ & $7.79,61659500.19^{*}$ & $\mathrm{ND}, 0.00^{*}$ \\
\hline Average & $5.29(5.74,4.23)$ & $7.27(7.26,7.28)$ & $7.64(7.66,7.62)$ & $6.97(2.45,7.15)$ \\
\hline SD & $5.93(6.17,4.63)$ & $7.38(7.15,7.45)$ & $7.86(7.58,7.93)$ & $7.63(2.88,7.72)$ \\
\hline Maximum & $6.59(6.59,5.11)$ & $7.92(7.57,7.92)$ & $8.51(7.99,8.51)$ & $8.29(3.3,8.29)$ \\
\hline Minimum & $\mathrm{ND}(\mathrm{ND}, \mathrm{ND})$ & $5.57(6.65,5.57)$ & $2.85(6.07,2.85)$ & $\mathrm{ND}(\mathrm{ND}, \mathrm{ND})$ \\
\hline Detection rate & $6 / 21(1 / 7,5 / 14)$ & $21 / 21(7 / 7,14 / 14)$ & $21 / 21(7 / 7,14 / 14)$ & $5 / 21(1 / 7,4 / 14)$ \\
\hline
\end{tabular}
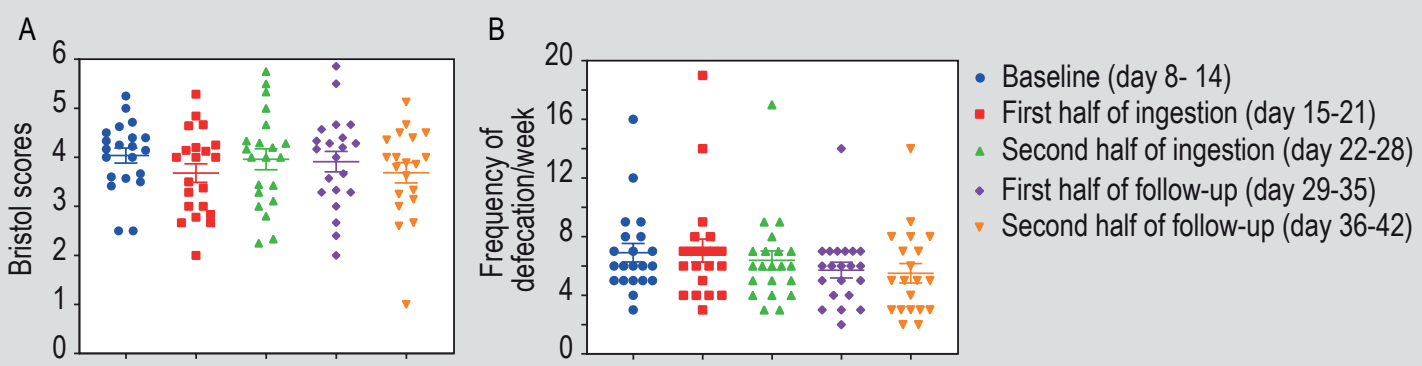

Figure 2. Scatter plots showing Bristol stool consistency scale (A) and frequency of defaecation per week (B). Mean values and standard error of the mean (SEM) are shown.

level of LcS could be influenced by individual dietary habit and lifestyle of Singaporeans. Some literature reports have shown a similar observation (Mai et al., 2017; Utami et al., 2015). As shown in Table 2, there is a large difference among individuals in the pattern of LcS recovery during the study period although the factor causing individual variation is not clear. 
Table 3. Summary of effect of Lactobacillus casei strain Shirota on the individual data of average Bristol stool consistency scores and frequency of defecation per week.

\begin{tabular}{|c|c|c|c|c|c|c|c|c|c|c|}
\hline \multirow[t]{2}{*}{$\begin{array}{l}\text { Subject } \\
\text { ID }\end{array}$} & \multicolumn{2}{|c|}{$\begin{array}{l}\text { Baseline } \\
\text { (day 8-14) }\end{array}$} & \multicolumn{2}{|c|}{$\begin{array}{l}\text { First half of ingestion } \\
\text { (day 15-21) }\end{array}$} & \multicolumn{2}{|c|}{$\begin{array}{l}\text { Second half of ingestion } \\
\text { (day 22-28) }\end{array}$} & \multicolumn{2}{|c|}{$\begin{array}{l}\text { First half of follow-up } \\
\text { (day 29-35) }\end{array}$} & \multicolumn{2}{|c|}{$\begin{array}{l}\text { Second half of follow-up } \\
\text { (day } 36-42 \text { ) }\end{array}$} \\
\hline & Scores & $\begin{array}{l}\text { Frequency of } \\
\text { defecation }\end{array}$ & Scores & $\begin{array}{l}\text { Frequency of } \\
\text { defecation }\end{array}$ & Scores & $\begin{array}{l}\text { Frequency of } \\
\text { defecation }\end{array}$ & Scores & $\begin{array}{l}\text { Frequency of } \\
\text { defecation }\end{array}$ & Scores & $\begin{array}{l}\text { Frequency of } \\
\text { defecation }\end{array}$ \\
\hline S1 & 4.14 & 7 & 2.78 & 9 & 3.44 & 9 & 3.57 & 7 & 3.63 & 8 \\
\hline S2 & 4.71 & 7 & 4.67 & 6 & 4.17 & 6 & 2.67 & 3 & 4.40 & 5 \\
\hline S3 & 4.00 & 5 & 4.14 & 7 & 4.00 & 5 & 4.17 & 6 & 4.00 & 5 \\
\hline S4 & 3.42 & 12 & 2.67 & 3 & 4.33 & 3 & 3.67 & 3 & 3.80 & 5 \\
\hline S5 & 4.22 & 9 & 4.13 & 8 & 3.29 & 7 & 4.67 & 6 & 4.50 & 2 \\
\hline S6 & 5.00 & 5 & 4.00 & 6 & 4.20 & 5 & 4.67 & 6 & 4.50 & 2 \\
\hline S7 & 4.17 & 6 & 4.25 & 4 & 5.50 & 6 & 5.50 & 2 & 4.67 & 3 \\
\hline S8 & 3.50 & 6 & 2.00 & 4 & 2.25 & 4 & 2.00 & 4 & 3.33 & 3 \\
\hline S9 & 5.25 & 8 & 4.20 & 5 & 4.00 & 4 & 4.00 & 6 & 4.00 & 6 \\
\hline $\mathrm{S} 10$ & 4.63 & 16 & 4.84 & 19 & 4.29 & 17 & 4.57 & 14 & 4.36 & 14 \\
\hline S11 & 2.50 & 8 & 3.00 & 7 & 5.00 & 6 & 5.86 & 7 & 3.25 & 8 \\
\hline $\mathrm{S} 12$ & 3.67 & 6 & 4.64 & 14 & 5.75 & 8 & 4.29 & 7 & 5.13 & 8 \\
\hline $\mathrm{S} 13$ & 2.50 & 6 & 2.83 & 6 & 3.00 & 4 & 3.00 & 4 & 2.67 & 3 \\
\hline S14 & 4.40 & 5 & 2.67 & 6 & 2.80 & 5 & 2.40 & 5 & 1.00 & 3 \\
\hline S15 & 4.40 & 5 & 3.00 & 4 & 4.67 & 3 & 4.33 & 3 & - & - \\
\hline S16 & 4.00 & 3 & 3.50 & 4 & 5.33 & 6 & 4.40 & 5 & 3.00 & 4 \\
\hline S17 & 3.60 & 5 & 4.00 & 7 & 2.33 & 6 & 4.20 & 5 & 4.00 & 3 \\
\hline S18 & 4.25 & 4 & 5.29 & 7 & 3.11 & 9 & 3.33 & 6 & 2.60 & 5 \\
\hline S19 & 3.57 & 7 & 3.29 & 7 & 3.43 & 7 & 3.29 & 7 & 3.86 & 7 \\
\hline $\mathrm{S} 20$ & 4.33 & 9 & 4.00 & 7 & 4.00 & 7 & 4.29 & 7 & 3.89 & 9 \\
\hline S21 & 4.50 & 6 & 3.38 & 8 & 4.29 & 7 & 3.29 & 7 & 3.14 & 7 \\
\hline Average & 4.04 & 6.90 & 3.68 & 7.05 & 3.96 & 6.38 & 3.91 & 5.71 & 3.69 & 5.50 \\
\hline $\mathrm{SD}^{1}$ & 0.70 & 2.88 & 0.86 & 3.60 & 0.98 & 2.97 & 0.96 & 2.47 & 0.92 & 2.96 \\
\hline Maximum & 5.25 & 16 & 5.29 & 19 & 5.75 & 17 & 5.86 & 14 & 5.13 & 14 \\
\hline Minimum & 2.50 & 3 & 2.00 & 3 & 2.25 & 3 & 2.00 & 2 & 1.00 & 2 \\
\hline
\end{tabular}

${ }^{1} \mathrm{SD}=$ standard deviation.

In general, average stool consistency was in a normal range during the study period, but the average frequency of defecation seems to be reduced gradually throughout the ingestion period till the end of the study. However, the individual changes of defecation frequency might have varied as shown in Table 3 because of seasonal differences in subjects daily habits including food intake.

In our study, LcS administration did not alter the relative abundance of major gut microbiota at the genus level in the analysis of whole subjects (Figure 3 and Supplementary Tables S2, S5 and S8). Similarly, the overall diversity of gut microbiota did not change in $\mathrm{LcS}$ administration in a past study (Stadlbauer et al., 2015). Changes in the abundance of major gut microbiota may depend on the host factors: i.e. age, race, lifestyle, the health of human gut, overall health status, dietary habit and so on, and the type of host gut microbiome and foreign agent (the introduced bacteria) factors: i.e. the dose of LcS consumption, duration of feeding, time of feeding and adhesion property of LcS (Evivie et al., 2017; Ouwehand et al., 2001; Sanders, 2011). In the aspect of the microbial composition, most of Lactobacillus spp. are found in the small intestine (Reuter, 2001; Sandine, 1978). This enumeration of Lactobacillus based on its abundance in faeces might have under-represent changes in the small intestine. On the other hand, in the analysis of male and female, statistical differences between each time point were detected not only in Lactobacillus but also some genus but, there is not enough information to consider their biological and physiological significance.

However, we could see changes in the relative abundance of Lactobacillus among gut microbiota after LcS consumption. This result was supported by the data from the recovery 

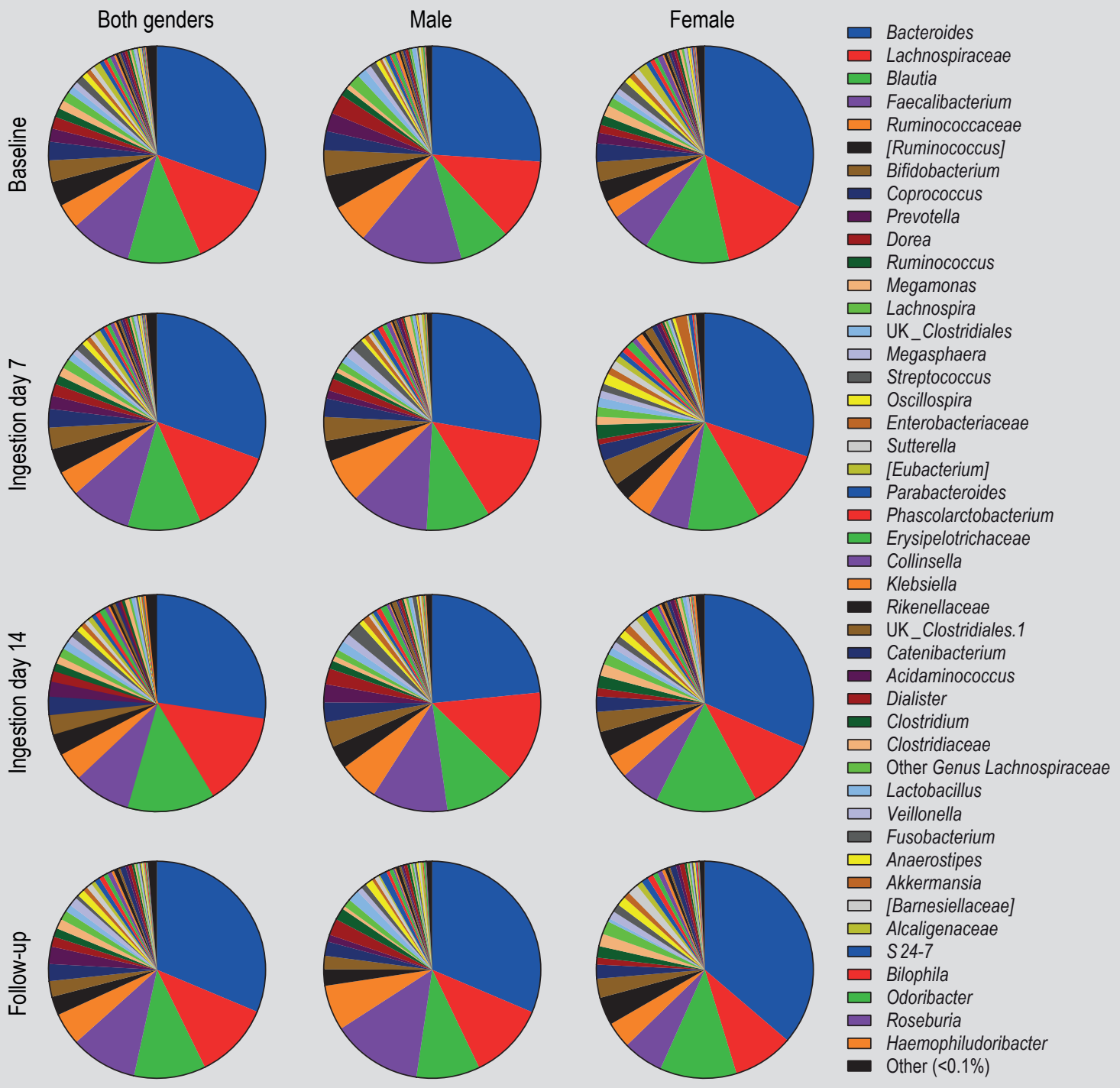

Figure 3. The composition of faecal microbiota in all the subjects at the genus level across the time points. Both genders, female and male plots are separated into 3 columns. The relative abundance of the genus $>0.1 \%$ is shown in the percentage for each time point. UK = unknown.

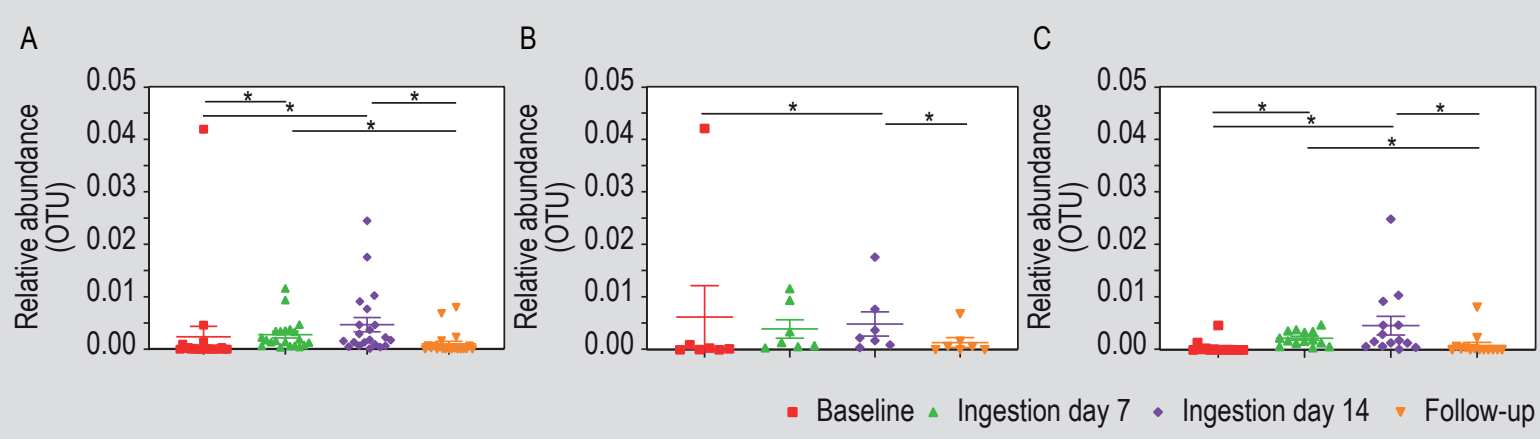

Figure 4. Comparison of the relative abundance of Lactobacillus across the time points for (A) both genders (B) male (C) female. The scatter plot shows the relative abundance of Lactobacillus at different time points. Mean and standard error of the mean (SEM) are shown. Asterisk represents significantly different at $P<0.05$ between the two time points. 
of LcS during the ingestion period detected by ELISA. Both ELISA and 16S rRNA could not detect LcS and Lactobacillus respectively in most of the subjects in the post-ingestion period. The method employed to analyse the faecal microbiota in this study did not allow identification of Lactobacillus species. LcS may have affected the commensal lactobacilli counts during its ingestion, but it was not clear in this study.

\section{Conclusions}

The study demonstrated that LcS can survive during passage through the gastrointestinal tract of Singapore adults and this confirms previous similar reports on the recovery of $\mathrm{LcS}$ in other countries. The study also showed that LcS is not able to colonise and persist in the intestinal tract of Singaporeans. Under this study condition, no interference by LcS on the major microbiota composition was observed and any probiotic effects of LcS on defecation due to modulation of gut microbiota profile was not observed in Singaporeans.

\section{Supplementary material}

Supplementary material can be found online at https://doi. org/10.3920/BM2018.0173.

Table S1. Results of permutational multivariate analysis of variance (PERMANOVA) of the gut microbial communities using Bray-Curtis distance.

Table S2. Results of Friedman rank sum test of major genus $(>0.1 \%$ in relative abundance) for both genders.

Table S3. Results of Friedman rank sum test of major genus $(>0.1 \%$ in relative abundance) for the female subjects.

Table S4. Results of Friedman rank sum test of major genus $(>0.1 \%$ in relative abundance) for the male subjects.

Table S5. Mean and standard deviation of relative abundance of genera of both genders.

Table S6. Mean and standard deviation of relative abundance of genera of female subjects.

Table S7. Mean and standard deviation of relative abundance of genera of female subjects.

Table S8. Results of Nemenyi PostHoc pairwise comparison test of major genus $(>0.1 \%$ in relative abundance) for both genders.

Table S9. Results of Nemenyi PostHoc pairwise comparison test of major genus ( $>0.1 \%$ in relative abundance) for the female subjects.
Table S10. Results of Nemenyi PostHoc pairwise comparison test of major genus $(>0.1 \%$ in relative abundance) for the male subjects.

\section{Acknowledgements}

We would like to acknowledge all the volunteers who contributed the samples in this study. We are greatly thankful to Yakult Honsha Co., Ltd. Tokyo, Japan which funded the study. Yakult drinks were provided by Yakult Singapore. We appreciate Yui, S., Shibata, H., Yap, C.M., Yuki, N., Takahashi, T., and Zhu, C.J. for their kind help throughout the study.

\section{References}

Aso, Y. and Akazan, H., 1992. Prophylactic effect of a Lactobacillus casei preparation on the recurrence of superficial bladder cancer. BLP Study Group. Urologia Internationalis 49: 125-129. https:// doi.org/10.1159/000282409

Caporaso, J.G., Kuczynski, J., Stombaugh, J., Bittinger, K., Bushman, F.D., Costello, E.K., Fierer, N., Pena, A.G., Goodrich, J.K., Gordon, J.I., Huttley, G.A., Kelley, S.T., Knights, D., Koenig, J.E., Ley, R.E., Lozupone, C.A., McDonald, D., Muegge, B.D., Pirrung, M., Reeder, J., Sevinsky, J.R., Turnbaugh, P.J., Walters, W.A., Widmann, J., Yatsunenko, T., Zaneveld, J. and Knight, R., 2010. QIIME allows analysis of high-throughput community sequencing data. Nature Methods 7: 335-336. https://doi.org/10.1038/nmeth.f.303

DeGruttola, A.K., Low, D., Mizoguchi, A. and Mizoguchi, E., 2016. Current understanding of dysbiosis in disease in human and animal models. Inflammatory Bowel Diseases 22: 1137-1150. https://doi. org/10.1097/MIB.0000000000000750

Evivie, S.E., Huo, G.C., Igene, J.O. and Bian, X., 2017. Some current applications, limitations and future perspectives of lactic acid bacteria as probiotics. Food and Nutrition Research 61: 1318034. https://doi.org/10.1080/16546628.2017.1318034

Guergoletto, K.B., Magnani, M., Martin, J.S., Andrade, C.G.T.d.J. and Garcia, S., 2010. Survival of Lactobacillus casei (LC-1) adhered to prebiotic vegetal fibers. Innovative Food Science and Emerging Technologies 11: 415-421. https://doi.org/10.1016/j.ifset.2009.11.003

Hemarajata, P. and Versalovic, J., 2013. Effects of probiotics on gut microbiota: mechanisms of intestinal immunomodulation and neuromodulation. Therapeutic Advances in Gastroenterology 6: 39-51. https://doi.org/10.1177/1756283X12459294

Kailasapathy, K. and Chin, J., 2000. Survival and therapeutic potential of probiotic organisms with reference to Lactobacillus acidophilus and Bifidobacterium spp. Immunology and Cell Biology 78: 80-88. https://doi.org/10.1046/j.1440-1711.2000.00886.x

Kechagia, M., Basoulis, D., Konstantopoulou, S., Dimitriadi, D., Gyftopoulou, K., Skarmoutsou, N. and Fakiri, E.M., 2013. Health benefits of probiotics: a review. ISRN Nutrition 2013: 481651. https://doi.org/10.5402/2013/481651 
Kuczynski, J., Stombaugh, J., Walters, W.A., Gonzalez, A., Caporaso, J.G. and Knight, R., 2011. Using QIIME to analyze 16S rRNA gene sequences from microbial communities. In: Current Protocols in Bioinformatics, Chapter 10: Unit 10.17. https://doi. org/10.1002/0471250953.bi1007s36

Lewis, S.J. and Heaton, K.W., 1997. Stool form scale as a useful guide to intestinal transit time. Scandinavian Journal of Gastroenterology 32: 920-924. https://doi.org/10.3109/00365529709011203

Mai, T.T., Hop, D.V., Anh, T.T. and Lam, N.T., 2017. Recovery of Lactobacillus casei strain Shirota (LcS) from the intestine of healthy Vietnamese adults after intake of fermented milk. Asia Pacific Journal of Clinical Nutrition 26: 72-77. https://doi.org/10.6133/ apjen.112015.09

Ouwehand, A.C., Tuomola, E.M., Tolkko, S. and Salminen, S., 2001. Assessment of adhesion properties of novel probiotic strains to human intestinal mucus. International Journal of Food Microbiology 64: 119-126.

Reuter, G., 2001. The Lactobacillus and Bifidobacterium microflora of the human intestine: composition and succession. Current Issues in Intestinal Microbiology 2: 43-53.

Rodriguez, J.M., Murphy, K., Stanton, C., Ross, R.P., Kober, O.I., Juge, N., Avershina, E., Rudi, K., Narbad, A., Jenmalm, M.C., Marchesi, J.R. and Collado, M.C., 2015. The composition of the gut microbiota throughout life, with an emphasis on early life. Microbial Ecology in Health and Disease 26: 26050. https://doi.org/10.3402/mehd. v26.26050

Sakai, T., Oishi, K., Asahara, T., Takada, T., Yuki, N., Matsumoto, K., Nomoto, K. and Kushiro, A., 2010. M-RTLV agar, a novel selective medium to distinguish Lactobacillus casei and Lactobacillus paracasei from Lactobacillus rhamnosus. International Journal of Food Microbiology 139: 154-160. https://doi.org/10.1016/j. ijfoodmicro.2010.03.019

Sanders, M.E., 2011. Impact of probiotics on colonizing microbiota of the gut. Journal of Clinical Gastroenterology 45 Suppl: S115-119. https://doi.org/10.1097/MCG.0b013e318227414a

Sandine, W.E., 1979. Roles of Lactobacillus in the Intestinal Tract. Journal of Food Protection 42: 259-262. https://doi. org/10.4315/0362-028x-42.3.259

Shida, K., Takahashi, R., Iwadate, E., Takamizawa, K., Yasui, H., Sato, T., Habu, S., Hachimura, S. and Kaminogawa, S., 2002. Lactobacillus casei strain Shirota suppresses serum immunoglobulin E and immunoglobulin G1 responses and systemic anaphylaxis in a food allergy model. Clinical and Experimental Allergy 32: 563-570.
Shu, Q. and Gill, H.S., 2002. Immune protection mediated by the probiotic Lactobacillus rhamnosus HN001 (DR20) against Escherichia coli O157:H7 infection in mice. FEMS Immunology and Medical Microbiology 34: 59-64. https://doi.org/10.1111/j.1574695X.2002.tb00603.x

Stadlbauer, V., Leber, B., Lemesch, S., Trajanoski, S., Bashir, M., Horvath, A., Tawdrous, M., Stojakovic, T., Fauler, G., Fickert, P., Hogenauer, C., Klymiuk, I., Stiegler, P., Lamprecht, M., Pieber, T.R., Tripolt, N.J. and Sourij, H., 2015. Lactobacillus casei Shirota supplementation does not restore gut microbiota composition and gut barrier in metabolic syndrome: a randomized pilot study. PLoS ONE 10: e0141399. https://doi.org/10.1371/journal.pone.0141399

Tiengrim, S., Leelaporn, A., Manatsathit, S. and Thamlikitkul, V., 2012. Viability of Lactobacillus casei strain Shirota (LcS) from feces of Thai healthy subjects regularly taking milk product containing LcS. Journal of the Medical Association of Thailand 95 Suppl 2: S42-47. Turnbaugh, P.J., Ley, R.E., Hamady, M., Fraser-Liggett, C.M., Knight, R. and Gordon, J.I., 2007. The human microbiome project. Nature 449: 804-810. https://doi.org/10.1038/nature06244

Utami, T., Cahyanto, M.N., Juffrie, M. and Rahayu, E.S., 2015. Recovery of Lactobacillus casei strain Shirota (LcS) from the intestine of healthy Indonesian volunteers after intake of fermented milk and its impact on the Enterobacteriaceae fecal microbiota. International Journal of Probiotics and Prebiotics 10: 77-84.

Wang, B., Yao, M., Lv, L., Ling, Z. and Li, L., 2017. The human microbiota in health and disease. Engineering 3: 71-82. https:// doi.org/10.1016/J.ENG.2017.01.008

Wang, R., Chen, S., Jin, J., Ren, F., Li, Y., Qiao, Z., Wang, Y. and Zhao, L., 2015. Survival of Lactobacillus casei strain Shirota in the intestines of healthy Chinese adults. Microbiology and Immunology 59: 268276. https://doi.org/10.1111/1348-0421.12249

Yuki, N., Watanabe, K., Mike, A., Tagami, Y., Tanaka, R., Ohwaki, M. and Morotomi, M., 1999. Survival of a probiotic, Lactobacillus casei strain Shirota, in the gastrointestinal tract: selective isolation from faeces and identification using monoclonal antibodies. International Journal of Food Microbiology 48: 51-57. https://doi.org/10.1016/ S0168-1605(99)00029-X

Ziemer, C.J. and Gibson, G.R., 1998. An overview of probiotics, prebiotics and synbiotics in the functional food concept: perspectives and future strategies. International Dairy Journal 8: 473-479. https:// doi.org/10.1016/S0958-6946(98)00071-5 